\title{
Evaluation of Serum Visfatin in Children and Adolescent with Type1 Diabetes Mellitus \\ Nahed Mahmoud Khater ${ }^{1}$, Hadeel Mohammed Abd ELrahman', Randa Hussieny Mohammed ${ }^{2}$, Mahmoud Ali Elashery*2
}

Departments of ${ }^{1}$ Pediatrics and ${ }^{2}$ Biochemistry, Faculty of Medicine - Zagazig University, Egypt

*Corresponding Author: Mahmoud Ali Elashery, Mobile: (+20)01093002398, Email: mahmoudelasheery@ gmail.com

\begin{abstract}
Background: Type 1 diabetes mellitus (T1DM) is a chronic illness characterized by the body's inability to produce insulin due to the autoimmune destruction of the beta cells in the pancreas. Visfatin is a ubiquitous intracellular enzyme, known as nicotine amide phosphoribosyl transferase (NAMPT) and pre-B-cell colony-enhancing factor (PBEF-1).

Objective: The aim of this study was to evaluate serum visfatin level in children and adolescent with type 1 diabetes mellitus (T1DM).

Patients and methods: The present study was a case-control study observation that was conducted in Pediatric Endocrinology Unit, Pediatric Ward, Zagazig University Hospitals. The study included 46 children; 23 with T1DM and 23 healthy age- and sex- matched children.

Results: In this study, we found that serum visfatin level in diabetic group is statistically highly significant lower than healthy group. The mean serum level of visfatin in healthy group was $19.53 \pm 10.5 \mathrm{ng} / \mathrm{ml}$, while in T1DM patients was $2.85 \pm 2.09 \mathrm{ng} / \mathrm{ml}$. The best cutoff of serum visfatin level in excluding T1DM was $\geq 3.6 \mathrm{ng} / \mathrm{ml}$ with area under curve 0.968 with sensitivity $91.3 \%$, specificity $82.6 \%$, positive predictive value $84 \%$, negative predictive value $90.5 \%$, positive likelihood ratio 5.25, negative likelihood ratio 0.11 and accuracy $87 \%(\mathrm{p}<0.001)$. The result showed that serum visfatin could be helpful in prediction of T1DM among children and adolescents with an accuracy $87 \%$.

Conclusion: Serum visfatin level is lower in T1DM patients compared to healthy control. Visfatin play a role in early prediction and understanding the mechanism of its action in T1DM could lead to new therapeutic targets.
\end{abstract}

Keywords: Visfatin, Pediatric, Type1 Diabetes mellitus, Assessment.

\section{INTRODUCTION}

Type 1 diabetes mellitus (T1DM) is a chronic illness characterized by the body's inability to produce insulin due to the autoimmune destruction of the beta cells in the pancreas ${ }^{(1)}$. Internationally the rates of T1DM are increasing. In Europe, Middle East, and Australia. T1DM is increasing by $2-5 \%$ per year ${ }^{(2)}$. T1DM is associated with a high morbidity and premature mortality. More than $60 \%$ of patients with T1DM do not develop serious complications over the long-term, but many experience blindness, end-stage renal disease (ESRD), and, in some cases, early death. The risk of ESRD and proliferative retinopathy is twice as high in men as in women when the onset of diabetes occurs before age 15 years ${ }^{(3)}$.

Complications of T1DM include hypoglycemia from management errors, increased risk of infections, microvascular complications (retinopathy and nephropathy), neuropathic complications and macrovascular disease ${ }^{(3)}$.

Adipose tissue secretes numerous bioactive peptides called 'adipokines'. Visfatin is a ubiquitous intracellular enzyme, known as nicotine amide phosphoribosyl transferase (NAMPT) and pre-B-cell colony-enhancing factor (PBEF-1). It is also identified as a novel adipocytokine ${ }^{(4)}$. Although the metabolic function of visfatin is still unknown, it appears that this newly identified adipocytokine might play an important role, similar to that of leptin, in the regulation of body weight, i.e. as an afferent signal reflecting excess body fat. The PBEF gene encodes a polypeptide of 491 amino acid residues. The secreted form of this polypeptide, i.e. visfatin, contains 465 residues and lacks the first $26 \mathrm{~N}$-terminal residues of the PBEF gene product ${ }^{(5)}$.

Recently, visfatin was isolated from visceral fat deposits. Like insulin, visfatin exerts hypoglycemic effects by interacting with the insulin receptor. The binding affinity of visfatin for the insulin receptor is similar to that of insulin, but it does not compete with insulin, suggesting that the two proteins interact with different receptor sites ${ }^{(6)}$. Visfatin, have an insulinmimetic effects and lowers plasma glucose levels in mice via activating insulin receptor pathways ${ }^{(7)}$. Visfatin binds to the insulin receptor at a site distinct from insulin and stimulates phosphorylation of the insulin receptor, insulin receptor substrate 1 and 2 (IRS-1 and IRS-2), and the binding of phosphatidylinositol-3-kinase to IRS-1 and IRS-2 ${ }^{(8)}$.

The aim of this study was to evaluate serum visfatin level in children and adolescents with Type 1 diabetes mellitus (T1DM).

\section{PATIENTS AND METHODS}

This study is a case-control study. It was conducted at the Pediatric Endocrinology Unit, Pediatric Ward, Zagazig University Hospitals through the period from March 2019 to March 2020. 
The study included 23 patients with T1DM, their ages ranged from 1.25-16 years old (mean 8.1 years old), 12 of them were males and 11 were females. In addition, 23 healthy children served as a control group, their ages ranged from 3-12 years (mean age 6.8 years old), 11 of them were males and 12 were females.

Inclusion criteria: Children and adolescents with type 1 diabetes mellitus, and patient at age (1-18) years.

Exclusion criteria: T2DM, malignancy and immunecompromised patients, acute or chronic diseases, any other endocrine diseases, and any other renal pathology.

All diabetic children were subjected to the following:

1) Full history taking stressing on age, sex, duration of diabetes, and symptoms suggestive of microvascular diabetic complications including diabetic retinopathy, diabetic nephropathy and diabetic neuropathy.

2) Complete physical examination including general examination [Vital signs as pulse (rate/min), blood pressure measurement (systolic and diastolic)]. Anthropometric measurements [Weight $(\mathrm{Kg})$ : children were weighed wearing light clothes and without shoes to the nearest $0.5 \mathrm{~kg}$. Height / length $(\mathrm{m})$ : Length for children less than 2 years old is measured lying down, while standing height is measured for children age 2 years or older. Height was assessed without shoes, the child stands with his heels together stretching upward to full extent and the back is straight as possible. Body mass index was calculated as BMI $=$ weight $(\mathrm{kg}) /$ height $\left(\mathrm{m}^{2}\right)$.

Laboratory investigations included Glycosylated haemoglobin (HbAlc), serum creatinine, BUN, serum albumin, urinary albumin, alb/creatinine ratio, GFR, and visfatin by ELISA: Determination of serum visfatin level by collecting samples of 3-5 $\mathrm{ml}$ venous blood that was left for coagulation at room temperature 10-20 minutes, then centrifugation for 20-min. At the speed of 2000-3000 r.p.m., then remove supernatant, if precipitation appeared centrifuge again. Plasma visfatin levels were measured using ELISA kits of human Visfatin (VF) ELISA Kit.

\section{Chemical Method:}

The quantity of the plates depends on the quantities of samples to-be-tested and the standards. It is suggested to duplicate each standard and blank well. Every sample was made according to the required quantity, and try to use the duplicated well as possible.

\section{Ethical consent:}

An approval of the study was obtained from Zagazig University Academic and Ethical
Committee. Every patient signed an informed written consent for acceptance of the study. This work has been carried out in accordance with The Code of Ethics of the World Medical Association (Declaration of Helsinki) for studies involving humans.

\section{Statistical Analysis}

Results of the presented study were collected and statistically analyzed using SPSS (statistical program of social science, (IBMO Corp., Armonk, NY, USA). The following statistical tests were used. Normality of numerical data distribution was tested using The D'Agostino-Pearson test. Description of quantitative variables as mean and SD. Description of qualitative variables as number and percentage. Unpaired student$t$ test was used to compare quantitative variables in parametric data (SD $<25 \%$ mean). Chi-square test was used to compare qualitative data. Ranked spearman correlation test to study the association between variables among each group. Receiver-operating characteristic (ROC) curve analysis was used to examine the value of continuous variables for prediction of binary outcomes. The DeLong method was used to compare the areas under the curve (AUC) for any pair of ROC curves. $\mathrm{P}$ value $\leq 0.05$ was considered significant.

\section{RESULTS}

Table (1) showed a statistically nonsignificant difference between the studied groups regarding gender, age and BMI. 12 patients had been diagnosed with T1DM in the first visit (newly discovered), while 11 patients had T1DM for duration ranged from 3 weeks to 5 years with mean duration $2.56 \pm 1.56$ years.

Table (2) showed a statistically highly significant difference in $\mathrm{HbA} 1 \mathrm{c}$ between the studied groups and a statistically significant difference between the studied groups regarding serum creatinine and eGFR. There was a statistically non-significant difference between groups regarding serum albumin, urinary albumin, BUN, Albumin/creatinine ratio, and presence of albuminuria.

Table (3) showed that there was a statistically highly significant difference between the studied groups regarding serum visfatin level (significantly lower in diabetic group).

Table (4) showed that the best cutoff of serum visfatin level in excluding T1DM was $\geq 3.6 \mathrm{ng} / \mathrm{ml}$ with area under curve 0.968 with sensitivity of $91.3 \%$, specificity of $82.6 \%$, positive predictive value of $84 \%$, negative predictive value of $90.5 \%$, positive likelihood ratio of 5.25, negative likelihood ratio of 0.11 and accuracy of $87 \%(\mathrm{p}<0.001)$. 
Table (1): Comparison between the studied groups regarding demographic characteristics and BMI

\begin{tabular}{|c|c|c|c|c|}
\hline & $\begin{array}{c}\text { Diabetic group } \\
\mathrm{N}=23(\%)\end{array}$ & $\begin{array}{c}\text { Control group } \\
\mathrm{N}=23(\%)\end{array}$ & $\mathrm{X}^{2} / \mathrm{Z} / \mathrm{t}$ & $\mathbf{P}$ \\
\hline $\begin{array}{l}\text { Gender } \\
\text { - Male } \\
\text { - Female }\end{array}$ & $\begin{array}{l}12(52.2) \\
11(47.8)\end{array}$ & $\begin{array}{l}11(47.8) \\
12(52.2)\end{array}$ & $X^{2}=0.087$ & 0.768 \\
\hline $\begin{aligned} & \text { Age (years) } \\
&- \text { Mean } \pm \text { SD } \\
& \text { - } \text { Range } \\
&\end{aligned}$ & $\begin{array}{c}8.11 \pm 3.66 \\
1.25-16\end{array}$ & $\begin{array}{c}6.83 \pm 2.15 \\
3-12\end{array}$ & $\mathrm{Z}=-1.83$ & 0.067 \\
\hline $\begin{array}{l}\text { BMI }\left(\mathbf{k g} / \mathbf{m}^{2}\right) \\
\text { - Mean } \pm \text { SD }\end{array}$ & $16 \pm 2.04$ & $16.63 \pm 1.29$ & $\mathrm{t}=-1.23$ & 0.226 \\
\hline
\end{tabular}

Table (2): Comparison between the studied groups regarding HbAlc and kidney function tests

\begin{tabular}{|c|c|c|c|c|}
\hline \multirow{3}{*}{ kidney function test: } & \multirow{3}{*}{$\begin{array}{c}\text { Diabetic group } \\
\mathrm{N}=23(\%)\end{array}$} & \multirow{3}{*}{$\begin{array}{c}\text { Control group } \\
\mathrm{N}=23(\%)\end{array}$} & \multicolumn{2}{|c|}{ Test } \\
\hline & & & \multirow{2}{*}{$\mathrm{X}^{2} / \mathrm{Z} / \mathrm{t}$} & \multirow{2}{*}{$\mathbf{P}$} \\
\hline & & & & \\
\hline $\begin{array}{l}\text { - Absent } \\
\text { - Present }\end{array}$ & $\begin{array}{l}19(82.6) \\
4(17.4)\end{array}$ & $\begin{array}{c}23(100) \\
0(0)\end{array}$ & Fisher & 0.109 \\
\hline $\begin{array}{l}\text { Urine albumin }(\mathbf{m c g} / \mathrm{ml}) \\
\text { - } \\
\text { Mean } \pm \text { SD }\end{array}$ & $26.97 \pm 36.58$ & $13 \pm 3.69$ & -0.519 & 0.604 \\
\hline $\begin{array}{ll} & \text { Serum albumin }(\mathbf{g} / \mathbf{d l}) \\
\text { - } & \text { Mean } \pm \mathrm{SD}\end{array}$ & $3.99 \pm 0.48$ & $3.92 \pm 0.14$ & 0.671 & 0.508 \\
\hline $\begin{array}{l}\text { BUN }(\mathbf{m g} / \mathbf{d l}) \\
\text { - } \\
\text { Mean } \pm \mathrm{SD}\end{array}$ & $6.48 \pm 3.61$ & $5.58 \pm 1.42$ & $Z(-0.264)$ & 0.792 \\
\hline $\begin{array}{l}\text { Serum creatinine(mg/dl) } \\
\text { - } \text { Mean } \pm \text { SD } \\
\end{array}$ & $0.81 \pm 0.13$ & $0.66 \pm 0.22$ & $\mathrm{Z}(-2.93)$ & 0.003 \\
\hline $\begin{array}{ll} & \text { eGFR(ml/min/1.73m) } \\
\text { - } & \text { Mean } \pm \mathrm{SD} \\
\end{array}$ & $126.89 \pm 21.98$ & $145.53 \pm 31.58$ & 2.324 & 0.025 \\
\hline $\begin{array}{l}\text { Albumin/creatinine ratio } \\
\text { (mg/dl) } \\
\text { - Mean } \pm \mathrm{SD}\end{array}$ & $0.11 \pm 0.02$ & $0.12 \pm 0.03$ & -1.361 & 0.18 \\
\hline $\begin{array}{ll} & \text { HbA1c }(\%) \\
- & \text { Mean } \pm \text { SD } \\
\end{array}$ & $10.75 \pm 0.48$ & $4.96 \pm 0.19$ & 53.942 & $<0.001$ \\
\hline
\end{tabular}

Table (3): Comparison between the studied groups regarding serum Visfatin level

\begin{tabular}{||c|c|c|c|c|}
\hline \multirow{2}{*}{$\begin{array}{c}\text { Serum visfatin level } \\
(\mathbf{n g} / \mathbf{m l})\end{array}$} & Diabetic group & Control group & \multicolumn{2}{|c|}{ Test } \\
\cline { 2 - 3 } & $\mathbf{N = 2 3}$ & $\mathbf{N}=\mathbf{2 3}$ & $\mathbf{Z}$ \\
\hline $\begin{array}{l}\text { Mean } \pm \text { SD } \\
\text { Median }\end{array}$ & $2.85 \pm 2.09$ & $19.53 \pm 10.5$ & & \\
\hline
\end{tabular}

Table (4): Performance of serum visfatin level in differentiating healthy from diabetic patient

\begin{tabular}{|c|c|c|c|c|c|c|c|c|c|}
\hline Cutoff & AUC & Sensitivity & Specificity & PPV & NPV & +LR & -LR & Accuracy & P \\
\hline$\geq 3.6$ & 0.968 & 91.3 & 82.6 & 84 & 90.5 & 5.25 & 0.11 & 87 & $<\mathbf{0 . 0 0 1}$ \\
\hline
\end{tabular}




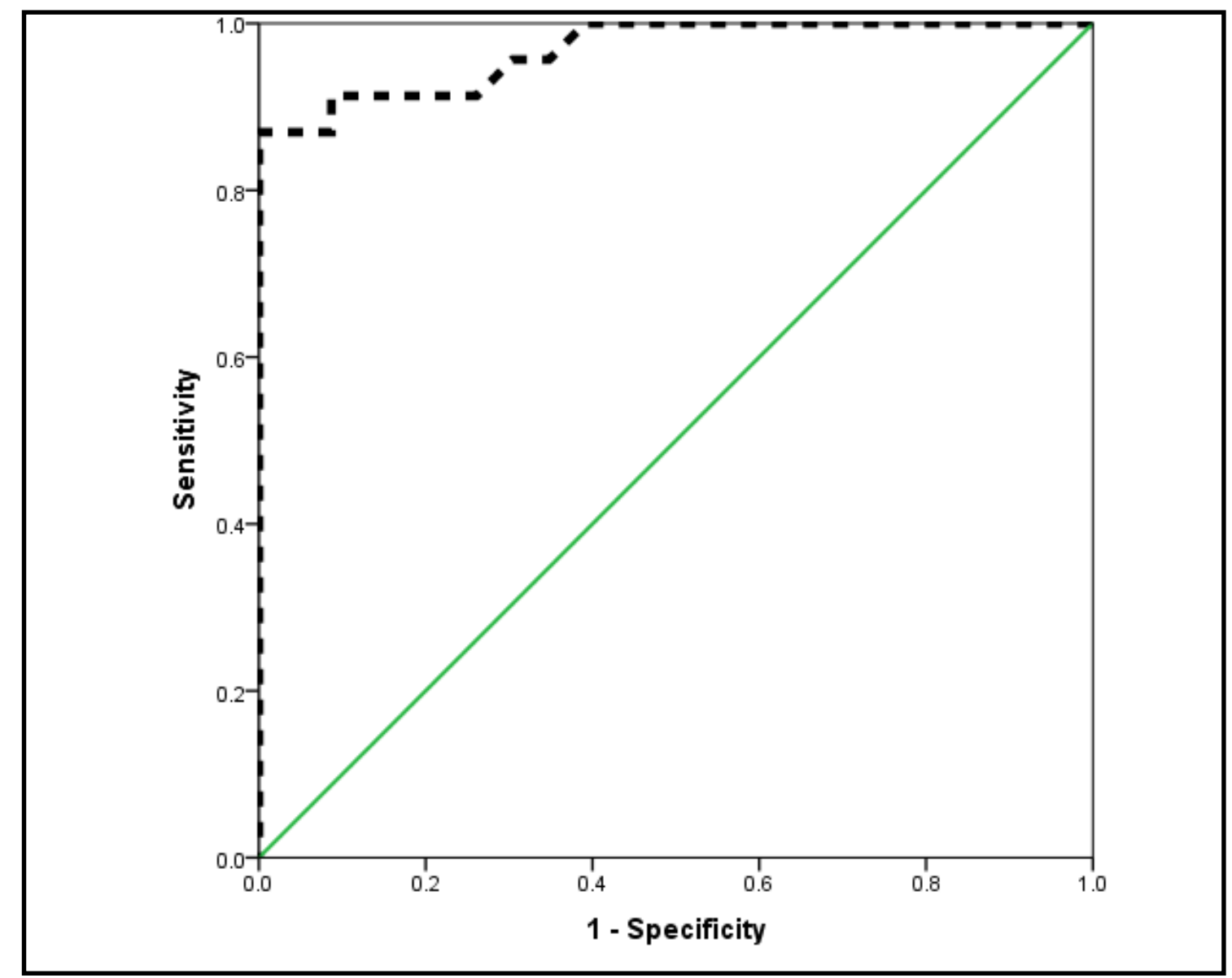

Fig. (1): ROC curve showing performance of serum visfatin level in differentiating healthy persons from diabetic subjects.

\section{DISCUSSION}

In this study, there was no significant difference between the two studied groups as regarding demographic and anthropometric measures; age, gender or BMI, which makes our study cross-matched. Our result is in agreement with Alexiadou et al. ${ }^{(9)}$ who examined 100 subjects with T1DM and 52 healthy controls and found non-significant deference among both subjects regarding age, gender and BMI. Similarly, Toruner et al. ${ }^{(10)}$ detected no statistical differences between the diabetic group and controls regarding age, sex and BMI in their study of 48 patients with T1DM and 26 healthy controls.

A statistically significant difference have been detected between studied groups regarding $\mathrm{HbAlc}$, serum creatinine and eGFR. HbAlc and serum creatinine level were higher, while eGFR was lower in diabetic patients than healthy control. HbA1c is a simple blood test that gives average blood sugar level over the past two to three months ${ }^{(11)}$. In this study, the HbA1c was higher in T1DM than healthy group (our healthy group were free from chronic disease and diabetes). Making our result come with the American Diabetes Association in diagnostic criteria of T1DM. Our result is in agreement with Bjornstad et al. ${ }^{(12)}$ who found that eGFR was lower in T1DM, while serum creatinine was higher in T1DM than healthy group. On the other hand our result disagrees with Sur (13) who studied 120 subjects (60 diabetics and 60 healthy) and found that no relationship in serum creatinine and eGFR between both groups (after excluding albuminuria).

Kidney function tests (eGFR, BUN and creatinine) in our diabetic patients are within normal, although GFR was lower and serum creatinine was higher in diabetic patients than in healthy. The normal finding of kidney functions maybe due to short course of the disease in our study ranged from 3 weeks to 5 years with mean duration $2.56 \pm 1.56$ years and exclusion of other risk factors like hypertension, chronic debilitating diseases and other metabolic diseases, which exacerbate diabetic nephropathy.

In this study, we find that serum visfatin level in diabetic group was statically highly significantly lower than healthy group. The mean serum level of visfatin in healthy group was $19.53 \pm 10.5 \mathrm{ng} / \mathrm{ml}$, while in T1DM patients was $2.85 \pm 2.09 \mathrm{ng} / \mathrm{ml}$. Our result is in agreement with El Samahi et al. ${ }^{(\mathbf{1 4})}$ who revealed that T1DM patients had a significantly lower visfatin level compared to the healthy control. In addition, Alexiadou et al. ${ }^{\left({ }^{(9)}\right.}$ found that visfatin levels tended to be lower in patients with T1DM compared to healthy subjects. Also Toruner et al. ${ }^{(10)}$ in their study on 48 T1DM and 26 healthy subjects reported that visfatin levels were lower in T1DM patients. On the other hand our result is in disagreement with Hontzsch et al. ${ }^{(15)}$ who found that children and adolescents with T1DM had higher visfatin levels compared to healthy group. 
Also AL-Suhaimi et al. ${ }^{(16)}$ measured serum visfatin among 28 Saudi pediatric volunteers consisted of 13 with T1DM and 15 healthy children. T1DM group had higher visfatin level than healthy group. Another study done by López-Bermejo et al. ${ }^{(17)}$ reported that serum visfatin increase with $\beta$-cell dysfunction both in longstanding T1DM patient and T2DM.

The reason of controversial data about visfatin concentrations in T1DM is not clear. This discrepancy may in part, be due to different study populations as our diabetic patients were younger and had a shorter duration of diabetes and higher $\mathrm{HbAlc}$ levels than the other studies.

The best cutoff of serum visfatin level in excluding T1DM was $\geq 3.6 \mathrm{ng} / \mathrm{ml}$ with area under curve 0.968 with sensitivity of $91.3 \%$, specificity of $82.6 \%$, positive predictive value of $84 \%$, negative predictive value of $90.5 \%$, positive likelihood ratio of 5.25 , negative likelihood ratio of 0.11 and accuracy of $87 \%(\mathrm{p}<0.001)$.

The result showed that serum visfatin could be helpful in prediction of T1DM among children and adolescents with an accuracy of $87 \%$.

\section{CONCLUSION}

Serum visfatin level is lower in T1DM patients compared to healthy control. Visfatin play a role in early prediction and understanding the mechanism of its action in T1DM that could lead to new therapeutic targets.

\section{Financial support and sponsorship: Nil. Conflict of interest: Nil.}

\section{REFERENCES}

1. Aathira R, Jain V (2014): Advances in management of type 1 diabetes mellitus. World Journal of Diabetes, 5 (5): 689.

2. Imkampe A, Gulliford M (2011): Trends in Type 1 diabetes incidence in the UK in 0-to 14-year-olds and in 15-to 34-year-olds, 1991-2008. Diabetic Medicine, 28 (7): 811-814.

3. Harjutsalo V, Forsblom C, Groop P (2011): Time trends in mortality in patients with type 1 diabetes: nationwide population based cohort study. BMJ., 343: 5364-69.

4. Adeghate E (2008): Visfatin: structure, function and relation to diabetes mellitus and other dysfunctions. Current Medicinal Chemistry, 15: 1851-1862.
5. Van den Bergh R, Morin S, Sass H et al. (2012): Monocytes contribute to differential immune pressure on R5 versus X4 HIV through the adipocytokine visfatin/NAMPT. PLoS One, 7 (4): 35074-79.

6. Moschen A, Kaser A, Enrich B et al. (2007): Visfatin, an adipocytokine with proinflammatory and immunomodulating properties. The Journal of Immunology, 178 (3): 1748-1758.

7. Pilz S, Mangge H, Obermayer-Pietsch B et al. (2007): Visfatin/pre-B-cell colony-enhancing factor: a protein with various suggested functions. Journal of Endocrinological Investigation, 30: 138-144.

8. Beltowski J (2006): Apelin and visfatin: unique. Medical Science Monitor, 12 (6): 112-119.

9. Alexiadou K, Kokkinos A, Liatis $\mathrm{S}$ et al. (2012): Differences in plasma apelin and visfatin levels between patients with type 1 diabetes mellitus and healthy subjects and response after acute hyperglycemia and insulin administration. Hormones, 11 (4): 444-450.

10. Toruner F, Altinova A, Bukan N et al. (2009): Plasma visfatin concentrations in subjects with type 1 diabetes mellitus. Hormone Research in Paediatrics, 72: 33-37.

11.ADA (American Diabetes Association) (2018): Classification and Diagnosis of Diabetes: Standards of Medical Care in Diabetes. American Diabetes Association, 41: 13-27.

12. Bjornstad P, Snell-Bergeon J, Rewers M et al. (2013): Early Diabetic Nephropathy: A complication of reduced insulin sensitivity in type 1 diabetes, Diabetes Care, 36 (11): 3678-3683.

13.Sur A (2016): Evaluation of serum creatinine and Cockcroft-Gault Estimated GFR as an Early Biomarker of Renal Impairment in Patients with Type 2 Diabetes Mellitus. J Clin Exp Nephrol., 1: 21-26.

14.El Samahi M, Ismail N, Matter R et al. (2017): Study of visfatin level in type 1 diabetic children and adolescents. Open access Macedonian Journal of Medical Sciences, 5 (3): 299-303.

15.Hontzsch J, Jasser-Nitsche $H$, Grillitsch $M$ et al. (2014): Children and Adolescents with Type 1 Diabetes have Higher Plasma Visfatin Levels than Healthy Controls. In ESPE 2014 (Vol. 82). European Society for Paediatric Endocrinology, 14: 123-130.

16. AL-Suhaimi E, AL-Kulaifi F, Ravinayagam $\mathrm{V}$ et al. (2012): Serum adipocytokines, metabolic and immunological correlations in type 1 diabetes mellitus (T1DM) children. The Open Endocrinology Journal, 6 (1): 1-6.

17.López-Bermejo A, Chico-Julià B, Fernàndez-Balsells $M$ et al. (2006): Serum visfatin increases with progressive $\beta$-cell deterioration. Diabetes, 55 (10): 28712875. 